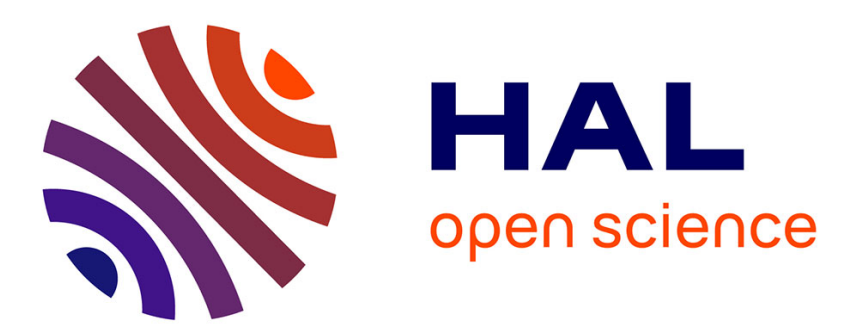

\title{
New chemotype of essential oil of Achillea santolina L. collected from different regions of Algeria
}

Tayeb Berramdane, Nadhir Gourine, Isabelle Bombarda, Mohamed Yousfi

\section{To cite this version:}

Tayeb Berramdane, Nadhir Gourine, Isabelle Bombarda, Mohamed Yousfi. New chemotype of essential oil of Achillea santolina L. collected from different regions of Algeria. Journal of Food Measurement and Characterization, 2018, 12 (3), pp.1779 - 1786. 10.1007/s11694-018-9793-5 . hal-01930264

\section{HAL Id: hal-01930264 \\ https://hal-amu.archives-ouvertes.fr/hal-01930264}

Submitted on 21 Nov 2018

HAL is a multi-disciplinary open access archive for the deposit and dissemination of scientific research documents, whether they are published or not. The documents may come from teaching and research institutions in France or abroad, or from public or private research centers.
L'archive ouverte pluridisciplinaire HAL, est destinée au dépôt et à la diffusion de documents scientifiques de niveau recherche, publiés ou non, émanant des établissements d'enseignement et de recherche français ou étrangers, des laboratoires publics ou privés. 


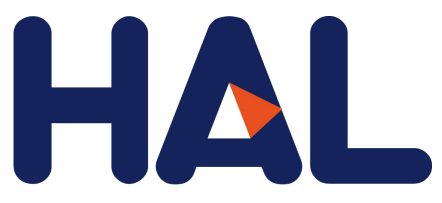

archives-ouvertes

\section{New chemotype of essential oil of Achillea santolina L. collected from different regions of Algeria}

Tayeb Berramdane, Nadhir Gourine, Isabelle Bombarda, Mohamed Yousfi

\section{To cite this version:}

Tayeb Berramdane, Nadhir Gourine, Isabelle Bombarda, Mohamed Yousfi. New chemotype of essential oil of Achillea santolina L. collected from different regions of Algeria. Journal of Food Measurement and Characterization, 2018, 12 (3), pp.1779 - 1786. <10.1007/s11694-018-9793-5>. <hal-01930264>

\section{HAL Id: hal-01930264 \\ https://hal-amu.archives-ouvertes.fr/hal-01930264}

Submitted on 21 Nov 2018

HAL is a multi-disciplinary open access archive for the deposit and dissemination of scientific research documents, whether they are published or not. The documents may come from teaching and research institutions in France or abroad, or from public or private research centers.
L'archive ouverte pluridisciplinaire HAL, est destinée au dépôt et à la diffusion de documents scientifiques de niveau recherche, publiés ou non, émanant des établissements d'enseignement et de recherche français ou étrangers, des laboratoires publics ou privés. 


\title{
New chemotype of essential oil of Achillea santolina L. collected from different regions of Algeria
}

\author{
Tayeb Berramdane $^{1} \cdot$ Nadhir Gourine ${ }^{1}\left[\right.$ [ Isabelle Bombarda ${ }^{2} \cdot$ Mohamed Yousfi $^{1}$
}

\begin{abstract}
Chemical composition of essential oil (EO) obtained by hydrodistillation of the aerial parts of Achillea santolina $\mathrm{L}$. was analysed using GC and GC-MS. Especially, this study involved a large scale investigation, using different regions in which, five flowering wild growing populations collected from the high plateau of Algeria were engaged. Unlike previous reports, the current investigation showed very high EO yields for this plant (up to $1.7 \% \mathrm{w} / \mathrm{w}$ "dw"). The main result of the current study was the occurrence of a new chemotype rich in camphor (39.54-67.86\%) and 1,8-cineole (7.14-8.57\%).
\end{abstract}

Keywords Achillea santolina L. Algeria · Essential oil · Chemical composition · Chemotype $\cdot$ Yield

\section{Introduction}

The genus Achillea is one of the most important genres of the Asteraceae family and comprises 115 species, which are mainly distributed in Europe, Asia and North Africa [1]. There are about five species of Achillea which are widely distributed in Algeria; A. ligustica All., A. leptophylla M.B., A. odorata L., A. santolinoïdes Lag. and A. santolina L. [2].

The aerial parts of different species of the genus Achillea are widely used in folk medicine due to various purposes and pharmacological properties in various biological activities, such as, anti-inflammatory [3], antimicrobial [4, 5], antispasmodic [6], antiulcer [7], and antiradical activities [8, 9]. Furthermore, this plant is also used as treatment for cancerous cells $[9,10]$. More specifically for A. santolina, the dried aerial parts and flowers of this plant were used traditionally as antidiabetic and as anti-inflammatory. It also used to relieve pain or dryness of the navel, stomach pain or gas and to relieve the symptoms of common cold [11]. Moreover, previous experimental investigations on A. santolina

Nadhir Gourine

n.gourine@lagh-univ.dz; gourine.nadir@gmail.com

$\triangle$ Mohamed Yousfi

yousfim8@gmail.com

1 Laboratoire des Sciences Fondamentales (LSF), Université Amar Télidji, Laghouat, BP. 37G, 03000 Laghouat, Algeria

2 Aix Marseille Univ, Univ Avignon, CNRS, IRD, IMBE, Marseille, France confirmed different biological and antioxidant activities of this plant $[8,11-23]$.

To our best knowledge, A. santolina growing in Algeria did not exhibit any studies concerning the chemical composition of their essential oil. At the opposite side, and according to literature, there were only few articles which reported the chemical composition of the essential oil of $A$. santolina coming from different countries of origin: Egypt [14, 22-24], Jordan [25] and Iran [26-28]. These reports revealed a high variability of the essential oil of A. santolina, which suggests the presence of different chemotypes for this plant, or at least indicates the presence of large chemical polymorphism within the population of this plant. The current investigation aims to identify the possible presence of new chemotype for the Algerian A. santolina essential oils.

\section{Materials and methods}

\section{Plant collection}

The aerial parts of A. santolina L. (at their full flowering phenological stage) were collected at the end of May 2014 from five different areas of the high plateaus; three from the wilaya of El-Bayadh (Tousmouline: R1, Mikther: R2, Bouzoulay: R3), and two from the wilaya of Laghouat (Lalmaya: R4 and Sidi Makhlouf: R5). More specifically, the geographical coordinates of the exact locations of these regions of collection and their altitudes, were summarized 
in Table 1. The plant was identified by Dr. Seridi abdel-kadir from Department of Agronomy, University of Laghouat. Voucher specimens have been deposited in the herbarium of the National Agronomic Institute of Algiers (N.A.I.), Algeria (Herbarium No. P: 11).

\section{Essential oil extraction}

The plant material samples were dried in a shade at ambient temperature; next they were carefully milled; after that they were hydrodistilled for $3 \mathrm{~h}$ using a Clevenger type apparatus. The essential oil samples were recovered from the distillate with diethyl-ether solvent and then dried overnight using anhydrous sodium sulfate $\mathrm{Na}_{2} \mathrm{SO}_{4}$. After filtration the extract solutions, they were reduced at room temperature under light vacuum pressure using rotary evaporator (rotavap). Finally, the obtained EO samples were stored at $\left(+4{ }^{\circ} \mathrm{C}\right)$ until analysis.

\section{Essential oil analysis}

Analysis was carried out by gas chromatography (GC) using two columns and by gas chromatography-mass spectroscopy (GC-MS).

\section{Gas chromatography (GC)}

For the first column (polar), a CP-Varian 3800 gas chromatograph was used with a flame ionization detector (FID), and a UB-Wax fused silica capillary column $(60 \mathrm{~m} \times 0.32 \mathrm{~mm}$, $0.25 \mu \mathrm{m}$ film thickness). Oven temperature was programmed from 50 to $250{ }^{\circ} \mathrm{C}$ at a rate of $3{ }^{\circ} \mathrm{C} \mathrm{min}^{-1}$ and held at $250{ }^{\circ} \mathrm{C}$ for $10 \mathrm{~min}$. Injector and detector temperatures were set at 250 and $260{ }^{\circ} \mathrm{C}$, respectively. Helium was the carrier gas at a flow rate of $1 \mathrm{ml} \mathrm{min}{ }^{-1}$. Splitting ratio 1:50.

For the second column (apolar), analytical GC was carried out in a Hewlett-Packard 6890 (Agilent Technologies, Palo Alto, CA, USA) gas chromatograph with a HP GC ChemStation Rev. A.05.04 data handling system, equipped with a single injector and flame ionization detection (FID) system. A graphpak divider (Agilent Technologies, part no. 5021-7148) was used for sampling to fused silica capillary column HP-5 (polydimethylsiloxane $30 \mathrm{~m} \times 0.20 \mathrm{~mm}$ i.d., film thickness $0.20 \mu \mathrm{m})$. Oven temperature program: $70-220{ }^{\circ} \mathrm{C}\left(3{ }^{\circ} \mathrm{C} \mathrm{min}{ }^{-1}\right), 220{ }^{\circ} \mathrm{C}(15 \mathrm{~min})$; injector temperature: $250{ }^{\circ} \mathrm{C}$; carrier gas: helium, adjusted to a linear velocity of $30 \mathrm{~cm} \mathrm{~s}^{-1}$; splitting ratio $1: 40$; detectors temperature: $250{ }^{\circ} \mathrm{C}$.

\section{Gas chromatography-mass spectroscopy (GC-MS)}

GC-MS was carried out in a Hewlett-Packard 6890 gas chromatograph fitted with a HP-1 fused silica column (polydimethylsiloxane $30 \mathrm{~m} \times 0.25 \mathrm{~mm}$ i.d., film thickness $0.25 \mu \mathrm{m}$ ), interfaced with an Hewlett-Packard mass selective detector 5973 (Agilent Technologies) operated by HP Enhanced ChemStation software, version A.03.00. GC parameters as described above; interface temperature: $250{ }^{\circ} \mathrm{C}$; MS source temperature: $230{ }^{\circ} \mathrm{C}$; MS quadrupole temperature: $150{ }^{\circ} \mathrm{C}$; ionization energy: $70 \mathrm{eV}$; ionization current: $60 \mu \mathrm{A}$; scan range: $35-350$ units; scans $\mathrm{s}^{-1}$ : 4.51 .

Components of each EO sample were identified by their linear retention indices on both UB-Wax and SPB-1 columns. Linear retention indices were calculated relative to linear homologous series of $n$-alkanes $\mathrm{C}_{8}-\mathrm{C}_{24}$. The identifications of the components were based on the comparison of their mass spectra with those of Wiley and NIST (National Institute of Standards and Technology) libraries, as well as by comparison of their retention indices with those of the values of a homemade database.

\section{Statistical analysis}

\section{Cluster analysis}

Cluster analysis was performed using AHC (Ward's technique) with Euclidean distance measure. The calculus was performed using two sets of data. The set of data which refer to the analysis of chemical composition of the essential oil of A. santolina, was composed of five different EO plant samples (from different regions of collection in Algeria). The total number of adopted variables was ten (representing simply the major identified components in all represented individuals, or the most influencing parameters that could make a difference i.e. some minor compounds).
Table 1 Characteristics of Achillea santolina $\mathrm{L}$. accessions used in this study

\begin{tabular}{|c|c|c|c|c|c|}
\hline $\begin{array}{l}\text { Attributed } \\
\text { region code }\end{array}$ & Origin & & Latitude & Longitude & Altitude (m) \\
\hline R1 & El-Bayadh & Tousmouline & $33^{\circ} 38^{\prime} 11.6^{\prime \prime} \mathrm{N}$ & $0^{\circ} 18^{\prime} 50.5^{\prime \prime} \mathrm{E}$ & 1191 \\
\hline $\mathrm{R} 2$ & & Mikther & $33^{\circ} 47^{\prime} 33.0^{\prime \prime} \mathrm{N}$ & $1^{\circ} 00^{\prime} 30.22^{\prime \prime} \mathrm{E}$ & 1223 \\
\hline R3 & & Bouzoulay & $34^{\circ} 01^{\prime} 43.8^{\prime \prime} \mathrm{N}$ & $0^{\circ} 57^{\prime} 36.6^{\prime \prime} \mathrm{E}$ & 1094 \\
\hline R4 & Laghouat & Lalmaya & $33^{\circ} 25^{\prime} 53.1^{\prime \prime} \mathrm{N}$ & $2^{\circ} 00^{\prime} 01.7^{\prime \prime} \mathrm{E}$ & 918 \\
\hline R5 & & Sidi Makhlouf & $34^{\circ} 7^{\prime} 39.45^{\prime \prime} \mathrm{N}$ & $3^{\circ} 00^{\prime} 53.2^{\prime \prime} \mathrm{E}$ & 881 \\
\hline
\end{tabular}




\section{Principal component analysis (PCA)}

The principal component analysis was performed using the same individuals and the same variables adopted for agglomerative hierarchical clustering method (as previously described).

\section{Results and discussion}

The essential oils isolated by hydrodistillation from plant samples harvested at their full flowering stage were obtained as pale yellow color. The obtained yields of the EO of the five different regions were different; they varied between 0.72 and $1.70 \%$ (Table 2). The determined yields of studied samples coming from different localities in Algeria revealed they were very rich in essential oil. The average calculated yield of these essential oils (expressed as mean $\pm \mathrm{SD}$ ) was equal to $1.06 \pm 0.39 \%$. These obtained values represented very high yields in comparison with the majority of previous reported works that dealt with the same plant material, but originating from different countries. More explicitly, the EO yield of the aerial parts of A. santolina from Jordan was found to be $0.18 \%$ [25]; for those of Iran (different localities) they were in the range of $0.10-0.60 \%[26,27]$. The EO yields of different parts of $A$. santolina; were also reported. They were identical for leaves, stems and flowers from Egypt (Sinai desert) with a yield values of $0.9 \%$ [14], but different for those coming from Iran: leaves $(1.5 \%)$, stems $(0.2 \%)$ and flowers (1.4\%) [28].

For the current study, the most important and the highest yield was recorded for the region of R4 (1.7\%), and the lowest one for the region of R5 (0.72\%); both regions belonged to the wilaya of Laghouat. The regions R2 and R3 showed practically similar yield values. The same previous observation could be extended to the yields of both $R 1$, and $R 5$ regions. The comparison of the maximum obtained yield with those of literature (no matter the studied parts: aerial or specific) revealed that it was $1.88(\approx 2)$ to 17 times higher than those of above mentioned reports [14, 25-28]. In fact, the mean yield value of all investigated samples $(1.06 \%)$ was the highest one, in comparison with all of those reported previously, for the same plant material. Moreover, the lowest yield (R5) was slightly lower than the highest yield $(0.9 \%)$ reported in literature [14].

When considering other species of Achillea as a purpose of yield comparison, the obtained yields values were also roughly equal or simply higher than those of other species rich in EO such as A. filipondila (0.76\%), A. pbrygia (0.70\%), and A. odorata (0.64-0.79\%) [29].

The essential oil compositions of the A. santolina samples considered for this study were characterized by the presence of high amounts of oxygen containing monoterpenes
(60.56-78.84\%) (Table 2). As matter of fact, the percentages of oxygenated monoterpenes were by far higher than monoterpenes hydrocarbons (2.34-10.64\%). In this case the most representative oxygenated monoterpenes was exclusively camphor (39.54-67.86\%). The percentages of total monterpenes were varying from 65.05 to $91.82 \%$. In another side, the percentages of oxygenated sesquiterpenes were most of the time very weak (max. 1.98\%). In this context, no sesquiterpenes hydrocarbons were detected this time.

The results brought by the current investigation on the chemical composition of the essential oils of A. santolina were different from those previously reported in literature. In fact, the determined values belonged to a new chemotype rich in camphor (39.54-67.86\%), with mean and standard deviation values of $(55.06 \pm 11.00 \%)$ and 1,8-cineole (7.14-8.57\%) with (mean $\pm \mathrm{SD}=7.70 \pm 0.65 \%$ ); and contain a minor compound $\alpha$-terpineol (1.24-4.16\%), which was practically absent in almost all previous reports, exception is made for the plant coming from Egypt [23] where its value was in the range of our presented work (Table 3). Moreover, the obtained percentages of some other minor compounds such as $\alpha$-pinene (1.05-2.52\%) and camphene (1.29-4.28\%), were slightly higher than those of previous reports dealing only with the aerial parts: ( $\alpha$-pinene: $0.0-0.6 \%$; camphene: $0.0-1.2 \%)$.

In order to determine, if exists, the similarities and/or the differences within the chemical compositions of the studied EO samples representing different regions of collection in Algeria, two powerful methods of multivariate statistical analysis were employed: AHC and principal component analysis (PCA). Besides, these two statistical methods were also engaged in highlighting the occurrence of the new Algerian chemoype taking in consideration the comparison of current values study with those of literature.

First, let's study both similarities and difference among the investigated Algerian EO samples. The results of AHC analysis represented by the dendrogram of the Fig. 1, showed the presence of two clusters regrouping (R1, R2, R3) and $(\mathrm{R} 4, \mathrm{R} 5)$, respectively. These result showed very good similarities among the three samples R1, R2 and R3, representing the region of El-Bayadh, and also for the samples R4 and $\mathrm{R} 5$, referring to the region of Laghouat, respectively. The difference between the two clusters R1, R2, R3 and R4, R5 is not obvious but existing (slight difference). $\mathrm{R} 4$ and $\mathrm{R} 5$ are exhibiting lower percentages of camphor $(39.54 \%$; $48.88 \%)$ in comparison with $\mathrm{R} 1,2,3$ samples (58.66-67.88\%). This quick and general inspection excludes the idea of the presence of more than one chemotype among the studied samples (only variability that exists). It can be clearly observed from the Table 3, that the Algerian samples were quite different from the rest of the reported samples.

These above observations for the studied samples were also confirmed by the results of PCA (Fig. 2), and 
Table 2 Essential oil composition of aerial parts of Achillea santolina L. from five different regions of collection in Algeria

\begin{tabular}{|c|c|c|c|c|c|c|c|c|c|}
\hline \multirow[t]{3}{*}{ No. } & \multirow[t]{3}{*}{ Components } & \multirow[t]{3}{*}{$\mathrm{LRI}^{\mathrm{a}}$} & \multirow[t]{3}{*}{$\mathrm{LRI}^{\mathrm{b}}$} & \multicolumn{5}{|c|}{ Composition $^{\mathrm{c}}$} & \multirow[t]{3}{*}{ Identification } \\
\hline & & & & \multicolumn{3}{|l|}{ El-Bayadh } & \multicolumn{2}{|l|}{ Laghouat } & \\
\hline & & & & $\begin{array}{l}\text { Tousmoul- } \\
\text { ine (R1) }\end{array}$ & Mikther (R2) & Bouzoulay (R3) & Lalmaya (R4) & $\begin{array}{l}\text { Sidi } \\
\text { Makhlouf } \\
\text { (R5) }\end{array}$ & \\
\hline 1 & Tricyclene & 1011 & 919 & 0.24 & 0.27 & 0.26 & - & - & MS, RI \\
\hline 2 & $\alpha$-Pinene & 1022 & 929 & 2.21 & 2.52 & 1.64 & 1.68 & 1.05 & MS, RI \\
\hline 3 & Camphene & 1061 & 942 & 3.28 & 3.47 & 4.28 & 2.89 & 1.29 & MS, RI \\
\hline 4 & $\beta$-Pinene & 1102 & 970 & 0.98 & 1.06 & 0.79 & 0.98 & - & MS, RI \\
\hline 5 & Sabinene & 1117 & 963 & 0.53 & 0.69 & 0.37 & 0.64 & - & MS, RI \\
\hline 6 & $\alpha$-Terpinene & 1184 & 1008 & 0.28 & 0.40 & 0.35 & - & - & MS, RI \\
\hline 7 & Limonene & 1206 & 1022 & 0.57 & 0.69 & 0.45 & 0.58 & - & MS, RI \\
\hline 8 & 1,8-Cineole & 1218 & 1018 & 8.22 & 8.57 & 7.29 & 7.14 & 7.29 & MS, RI \\
\hline 9 & $\gamma$-Terpinene & 1250 & 1046 & 0.68 & 0.52 & 0.63 & - & - & MS, RI \\
\hline 10 & $E$ - $\beta$-ocimene & 1277 & & 0.41 & - & 0.34 & & - & MS, RI \\
\hline 11 & $p$-Cymene & 1287 & 1011 & 0.16 & 0.81 & 0.24 & 1.30 & - & MS, RI \\
\hline 12 & $\alpha$-Terpinolene & 1299 & 1076 & 0.24 & 0.21 & 0.24 & - & - & MS, RI \\
\hline 13 & cis-Sabinene hydrate & 1510 & 1050 & 0.53 & 0.66 & 0.31 & 0.98 & 0.75 & MS, RI \\
\hline 14 & $\alpha$-Campholenal & 1493 & 1102 & 0.21 & - & - & - & - & MS, RI \\
\hline 15 & Camphor & 1518 & 1118 & 60.38 & 58.66 & 67.86 & 39.54 & 48.88 & MS, RI \\
\hline 16 & trans-Sabinene hydrate & 1544 & & 0.19 & - & 0.67 & - & - & MS, RI \\
\hline 17 & Linalool & 1550 & 1081 & 0.13 & - & - & - & - & MS, RI \\
\hline 18 & Pinocarvone & 1563 & 1133 & 0.12 & - & - & - & - & MS, RI \\
\hline 19 & cis-p-Menth-2-en-1-ol & 1577 & 1105 & 0.78 & 0.43 & - & 1.04 & - & MS, RI \\
\hline 20 & Bornyl acetate & 1592 & & 0.78 & 2.08 & - & - & - & MS, RI \\
\hline 21 & Terpinen-4-ol & 1615 & 1157 & 2.45 & 4.32 & - & 3.02 & 1.23 & MS, RI \\
\hline 22 & trans-p-Menth-2-en-1-ol & 1634 & & - & 0.21 & - & - & - & MS, RI \\
\hline 23 & Myrtenal & 1667 & 1163 & 0.21 & 0.24 & - & 2.97 & - & MS, RI \\
\hline 24 & $\alpha$-Terpineol & 1705 & & 4.61 & 1.24 & 1.43 & 2.15 & 3.01 & MS, RI \\
\hline 25 & cis-Verbenol & 1709 & & - & 0.40 & - & - & - & MS, RI \\
\hline 26 & Borneol & 1715 & 1133 & 0.34 & 0.22 & - & 1.65 & 2.30 & MS, RI \\
\hline 27 & Myrtenol & 1794 & 1175 & 1.39 & 1.12 & - & 3.05 & - & MS, RI \\
\hline 28 & Caryophyllene oxide & 1990 & & 1.61 & - & 0.74 & 1.98 & 0.85 & MS, RI \\
\hline 29 & Caryophyllenol II & 2230 & & 0.18 & - & - & - & - & MS, RI \\
\hline 30 & $E, E$-farnesyl acetate & 2279 & & 0.11 & 0.23 & - & 0.78 & 0.84 & MS, RI \\
\hline \multicolumn{2}{|c|}{ Total } & & & 91.82 & 89.02 & 87.89 & 72.37 & 67.49 & \\
\hline \multicolumn{2}{|c|}{ Monoterpene hydrocarbons } & & & 9.58 & 10.64 & 9.59 & 8.07 & 2.34 & \\
\hline \multicolumn{2}{|c|}{ Oxygen containing monoterpene } & & & 78.84 & 75.41 & 76.58 & 60.56 & 62.71 & \\
\hline \multicolumn{2}{|c|}{ Total monoterpenes } & & & 88.42 & 86.05 & 86.17 & 68.63 & 65.05 & \\
\hline \multicolumn{2}{|c|}{ Sesquiterpene hydrocarbons } & & & - & - & - & - & - & \\
\hline \multicolumn{2}{|c|}{ Oxygen containing sesquiterpene } & & & 1.79 & 0.00 & 0.74 & 1.98 & 0.85 & \\
\hline \multicolumn{2}{|c|}{ Total sesquiterpenes } & & & 1.79 & 0.00 & 0.74 & 1.98 & 0.85 & \\
\hline \multicolumn{2}{|c|}{ Esters } & & & 1.61 & 2.97 & 0.98 & 1.76 & 1.59 & \\
\hline \multicolumn{2}{|c|}{ Essential oil yield \% (w/w) } & & & 0.76 & 0.99 & 1.11 & 1.70 & 0.72 & \\
\hline
\end{tabular}

Compounds listed in order to their elution on the UB-Wax column column

${ }^{a}$ Linear retention indices on the UB-Wax column relative to $\mathrm{C}_{8}-\mathrm{C}_{24} n$-alkanes

${ }^{\mathrm{b}}$ Linear retention indices on the HP-5 column relative to $\mathrm{C}_{8}-\mathrm{C}_{24} n$-alkanes

${ }^{\mathrm{c}}$ Percentages obtained by FID peak-area normalization on UB-Wax column 


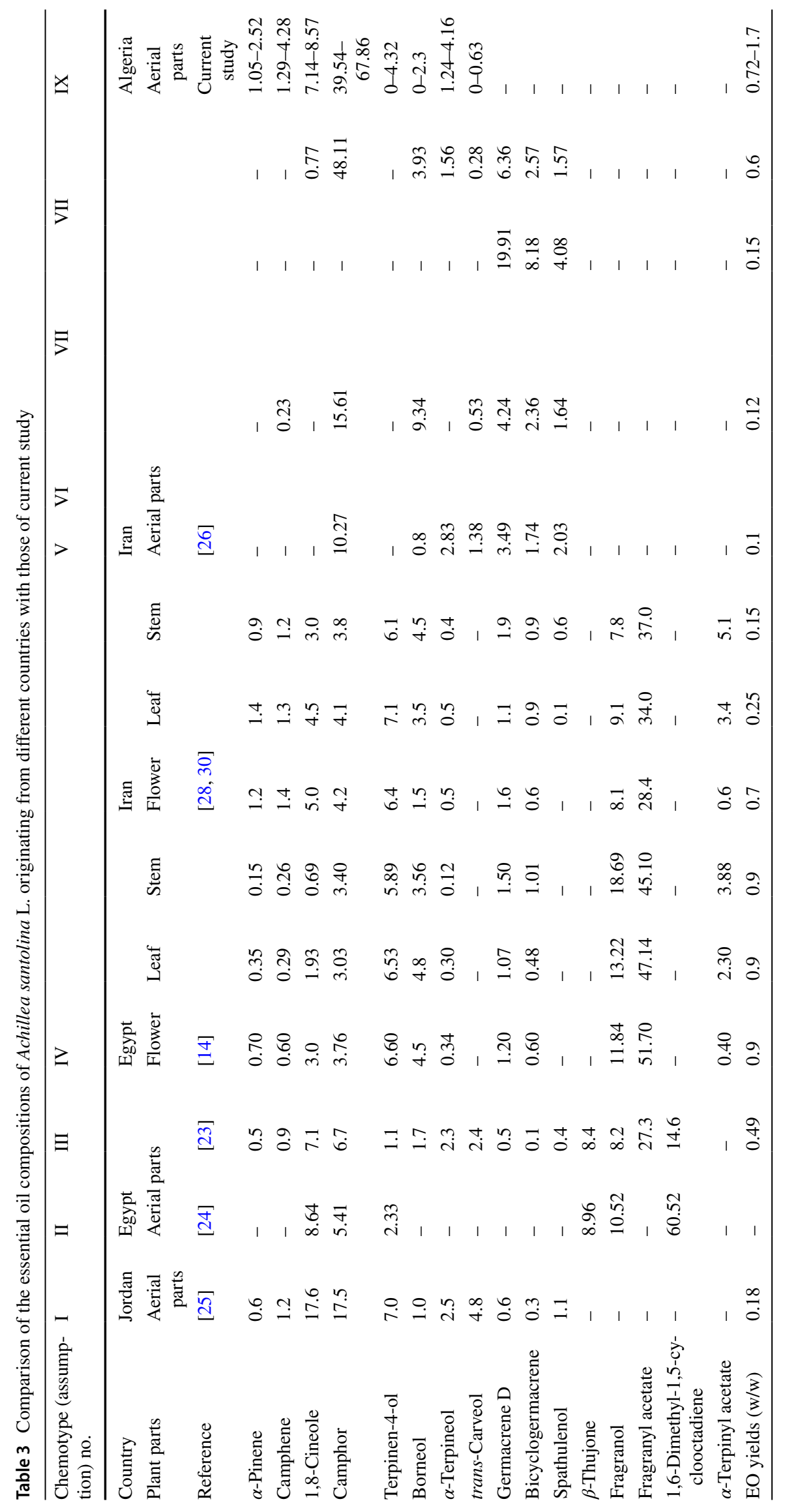


Fig. 1 Dendrogram obtained from a cluster analysis of five different Algerian essential oil samples of Achillea santolina L. Samples are clustered using Ward's technique with a Euclidean distance measure
Fig. 2 Two dimensional plots on axes F1 and F2 using PCA of five different Algerian essential oil samples of Achillea santolina $\mathrm{L}$.
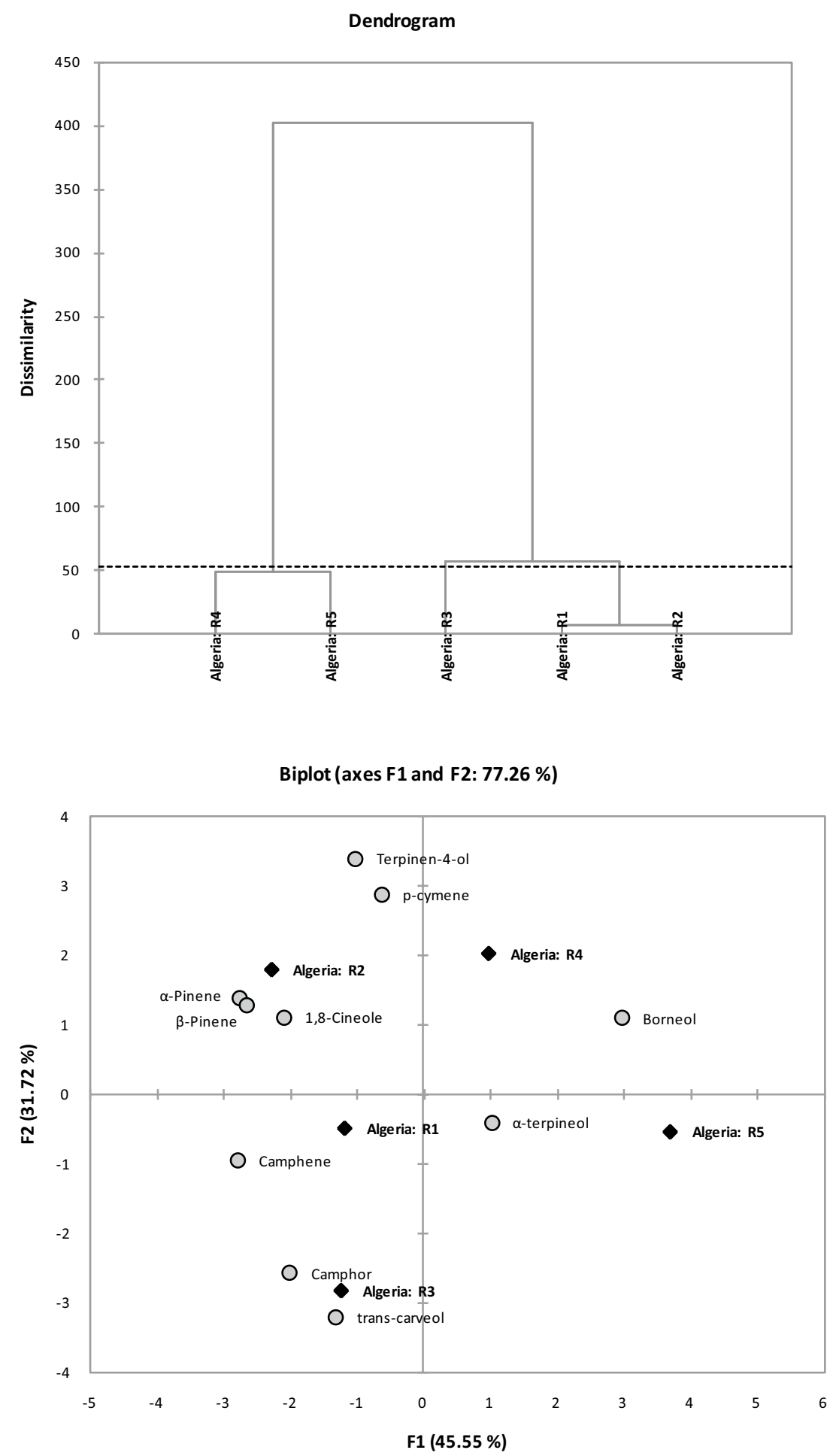

which allowed us to discuss the similarities and the differences upon the chemical compositions. Loading factors for principal axes F1 and F2 (representing 77.26\% of the total information), are given in Fig. 2. The F1 Axis, which represents $45.55 \%$ of the total information, is highly positively correlated with borneol (95.5\%), and also highly negatively correlated with $\alpha$-pinene $(-89.1 \%)$, camphene
$(-89.5 \%)$ and $\beta$-pinene (-85.7\%). In addition this axis is also in good correlation with 1,8-cineole (Table 5).

In another hand, axis F2, which represents $31.72 \%$ of the total information, is highly negatively correlated with trans-carveol $(-86.1 \%)$, and in good negative correlation with camphor $(-69.1 \%)$. At the opposite, this axis is 
strongly positively correlated with terpinen-4-ol (91.4\%) and $p$-cymene $(77.7 \%)$ (Table 5).

The values of the correlations of the compounds among each other and with the axis F1 and F2 were summarized in Tables 4 and 5.

As determined earlier by the AHC analysis, the samples R1-R5 (of Laghouat) were divided from the rest of the samples (R1, 2, 3 of El-Bayadh) by the first axis (F1). The PCA can provide more information's about the similarities and/or the differences between the samples. In fact, the samples studied herein this investigation can be distinguished mainly upon their composition variation relative to camphor "as major compound" and also relative to both terpinen-4-ol and borneol "as minor compounds", among others.

The examination of the data of current study with those of literature (According to Table 3), confirmed the occurrence of a new chemotype (camphor/1,8-cineole) native to Algeria, which was distinguished only by two major compounds which were camphor (39.54-67.86\%) and 1,8-cineole (7.14-8.57\%); and might also be distinguished by the minor compound $\alpha$-terpineol (1.24-4.16\%), which was determined in relatively higher percentages in comparison with those of literature reports. In fact, in previous studies $\alpha$-terpineol was not detected or at least was not detected at measurable percentages in most of case studies (Table 3).

Now let's try to identify (only by assumption) the possible existing chemotypes on the basis of the data provided by literature (Table 3). Upon the survey data presented in this table, the essential oils were distributed in eight chemotypes of A. santolina (Algerian samples are not included).

The first one is the Jordan chemotype (I) which enclosed four major compounds $\beta$-thujone/1,8-cineole/ camphor/terpinen-4-ol, in which the percentages of camphor and 1,8-cineole were very close to each other's (17.6 and $17.5 \%$, respectively). Before we proceed, lets mention that although they presented some similar percentages of fragranol $(8.20-18.69 \%$ or $12.49 \pm 3.93 \%)$, the samples
Table 5 Correlations between variables and factors (F1, F2) obtained by PCA method

\begin{tabular}{lll}
\hline & F1 & F2 \\
\hline$\alpha$-Pinene & -0.891 & 0.376 \\
Camphene & -0.895 & -0.254 \\
1,8-Cineole & -0.673 & 0.300 \\
Camphor & -0.651 & -0.691 \\
Terpinen-4-ol & -0.329 & 0.914 \\
Borneol & 0.955 & 0.295 \\
$\alpha$-Terpineol & 0.329 & -0.106 \\
trans-Carveol & -0.425 & -0.861 \\
$\beta$-Pinene & -0.857 & 0.343 \\
$p$-Cymene & -0.204 & 0.777 \\
\hline
\end{tabular}

from Egypt were presenting three different chemotypes (plant part was not considered).

The second chemotype found in Egypt that might be considered is: chemotype (II) rich in 1,6-dimethyl-1,5-cyclooctadiene $(60.52 \%)$, fragranol $(10.52 \%)$ and 1,8 -cineole $(8.64 \%)$ and $\beta$-thujone (8.96\%), but doesn't contain fragranyl-acetate.

The third chemotype (III) also from Egypt is very similar to the previous chemotype in almost all components, but the difference lies in lower percentage of 1,6-dimethyl-1,5-cyclooctadiene (14.6\%), and the occurrence of new component fragranyl-acetate with high amount (27.3\%) found also in similar amounts in the next chemotype (IV). In this case, the major components were fragranyl acetate (27.3\%), 6-dimethyl-1,5-cyclooctadiene (14.6\%), fragranol $(8.2 \%)$ and 1,8 -cineole (7.1\%), $\beta$-thujone (8.4\%) and camphor (6.7\%).

The forth chemotype (IV) belongs to both Egypt and Iran countries and was rich in fragranyl acetate (28.4-51.7\%) and fragranol (7.8-18.69\%). In addition, this chemotype did not contain 1,6-dimethyl-1,5-cyclooctadiene, but presented relatively important content of terpinen-4-ol (5.89-7.1\%), and doesn't contain $\beta$-thujone at all. Let's remind that the new

Table 4 Correlation matrix of the compounds of the essential oil of Achillea santolina L. obtained by PCA method

\begin{tabular}{|c|c|c|c|c|c|c|c|c|c|c|}
\hline Variables & $\alpha$-Pinene & Camphene & 1,8-Cineole & Camphor & Terpinen-4-ol & Borneol & $\alpha$-Terpineol & trans-Carveol & $\beta$-Pinene & $p$-Cymene \\
\hline$\alpha$-Pinene & 1 & & & & & & & & & \\
\hline Camphene & 0.615 & 1 & & & & & & & & \\
\hline 1,8-Cineole & 0.871 & 0.277 & 1 & & & & & & & \\
\hline Camphor & 0.369 & 0.656 & 0.417 & 1 & & & & & & \\
\hline Terpinen-4-ol & 0.693 & -0.025 & 0.655 & -0.355 & 1 & & & & & \\
\hline Bornol & -0.746 & -0.918 & -0.574 & -0.835 & -0.051 & 1 & & & & \\
\hline$\alpha$-Terpineol & -0.141 & -0.434 & 0.062 & -0.134 & -0.085 & 0.275 & 1 & & & \\
\hline trans-Carveol & 0.012 & 0.688 & -0.136 & 0.785 & -0.703 & -0.651 & -0.047 & 1 & & \\
\hline$\beta$-Pinene & 0.851 & 0.786 & 0.487 & 0.203 & 0.531 & -0.707 & -0.241 & 0.173 & 1 & \\
\hline p-Cymene & 0.329 & 0.203 & -0.031 & -0.561 & 0.637 & 0.052 & -0.464 & -0.446 & 0.599 & 1 \\
\hline
\end{tabular}


chemotype of Algeria did not contain neither 1,6-dimethyl1,5-cyclooctadiene, nor fragranyl-acetate or $\beta$-thujone.

Furthermore, it was observed that the samples coming from Iran were presenting lot of dissimilarities (five possible chemotypes), and were characterized by very low contents of 1,8-cineole (0.0-0.77\%). These chemotypes were somewhat unique: chemotype (V): camphor (10.27); chemotype (VI): camphor/borneol (15.61/9.34\%); chemotype (VII): camphor/ germacrene D (48.11/19.91\%); chemotype (VIII): germacrene D/bicyclogermacrene (19.91/8.18\%).

Finally, when referring also to Table 3 , we could notice that the Jordan sample is quiet similar to the Algerian samples (close chemotypes), this could be explained simply by the presence of some percentage similarities among several minor components i.e. $\alpha$-pinene, camphene, terpinen4-ol, borneol, $\alpha$-terpineol, trans-carveol, etc. In addition, and like the Algerian samples, the Jordan sample exhibited high percentages of 1,8-cineole and camphor, but the difference lies in their range variation values; for Jordan sample the percentage of 1,8 -cineole was $17.6 \%$ which is higher (almost twice times) than the range recorded for the samples of Algeria (7.14-8.57\%). Inversely the camphor which was present with almost the same percentage in Jordan sample (17.5\%), is now very low than recorded for the Algerian samples (39.54-67.86\%). In addition, the difference between the two chemotypes lies partially in the component terpinen4-ol. For Jordan chemoype the percentage of this component is considerably higher than those of Algeria (7.0\% vs. $0-4.32 \%$ ). Finally, it was observed that this chemotype (Jordan) is characterized by the relatively highest content of trans-carveol (4.8\%) in comparison with the rest of reported chemotypes $(0.0-2.4 \%)$.

\section{Conclusion}

The analysis of chemical composition of essential oils of A. santolina aerial parts showed the occurrence of a new chemotype "camphor/1,8-cineole", which was characterized by high amounts of two major compounds camphor (39.54-67.86\%) and 1,8-cineole (7.14-8.57\%).

For future perspectives, and upon the fact that the studied EOs revealed the presence of high amounts of oxygenated compounds or at least the presence of 1,8-cineole (Eucalyptol) in good amounts (besides the high EO yields), further studies involving the investigation of antimicrobial and/ or antioxidant activities are strongly advised for this new chemotype coming from Algeria.

\section{References}

1. K. Bremer, Asteraceae: Cladistics and Classification (Timber Press, Portland, 1994), pp. 377-434

2. P. Quézel, S. Santa, O. Schotter, Nouvelle flore de l'Algerie et des regions desertiques meridionales. Tome II. (Centre National de la Recherche Scientifique, Paris, 1962)

3. B. Benedek, B. Kopp, M.F. Melzig, J. Ethnopharmacol. 113, 312 (2007)

4. A. Sökmen, G. Vardar-Ünlü, M. Polissiou, D. Daferera, M. Sökmen, E. Dönmez, Phytother. Res. 17, 1005 (2003)

5. M. Ünlü, D. Daferera, E. Dönmez, M. Polissiou, B. Tepe, A. Sökmen, J. Ethnopharmacol. 83, 117 (2002)

6. S. Yaeesh, Q. Jamal, A.u.. Khan, A.H. Gilani, Phytother. Res. 20, $546(2006)$

7. H.I. Abd-Alla, N.M. Shalaby, M.A. Hamed, N.S. El-Rigal, S.N. Al-Ghamdi, J. Bouajila, Arch. Pharmacal Res. 39, 10 (2016)

8. A. Ardestani, R. Yazdanparast, Food Chem. 104, 21 (2007)

9. E.B. Bali, L. Açık, P. Elçi, M. Sarper, F. Avcu, M. Vural, Pharmacogn. Mag. 11, S308 (2015)

10. G. Ghavami, S. Sardari, M. Shokrgozar, J. Med. Plants Res. 4, $2411(2010)$

11. A.E. Al-Snafi, Int. J. PharmTech Res. 5, 1373 (2013)

12. A. Khalil, B.F. Dababneh, A.H. Al-Gabbiesh, J. Food Agric. Environ. 7, 103 (2009)

13. A. Alkofahi, R. Batshoun, W. Owais, N. Najib, Fitoterapia 67, 435 (1996)

14. A.M. El-Shazly, S.S. Hafez, M. Wink, Pharmazie 59, 226 (2004)

15. J. Zaringhalam, A. Akbari, E. Tekieh, H. Manaheji, S. Rezazadeh, J. Chin. Integr. Med. 8, 1180 (2010)

16. M.K. Al-Hindawi, I.H. Al-Deen, M.H. Nabi, M.A. Ismail, J. Ethnopharmacol. 26, 163 (1989)

17. N. Al-Awwadi, Int. J. Med. Plants Res. 2, 129 (2013)

18. A. Ardestani, R. Yazdanparast, Pharmacologyonline 3, 298 (2006)

19. V. Khoori, S. Nayebpour, Y. Ashrafian, M. Naseri, J. Gorgan Univ. Med. Sci. 1, 5 (1999)

20. N. Al-Awwadi, Thi-Qar Med. J. 4, 131 (2010)

21. H.A. Twaij, E.E. Elisha, A. Kery, A.-S. Faraj, Int. J. Crude Drug Res. 26, 169 (1988)

22. E.M. Ali, H. Abd El-Moaty, J. Essent. Oil Bear. Plants. 20, 1030 (2017)

23. G.E. Nenaah, J. Pest Sci. 87, 273 (2014)

24. M.I.E. Mohamed, S.A.M. Abdelgaleil, Appl. Entomol. Zool. 43, 599 (2008)

25. A. Bader, G. Flamini, P.L. Cioni, I. Morelli, Flavour Fragr J. 18, $36(2003)$

26. M. Rahimmalek, B.E.S. Tabatabaei, N. Etemadic, S.A.H. Goli, A. Arzani, H. Zeinali, Ind. Crops Prod. 29, 348 (2009)

27. M. Farajpour, M. Ebrahimi, R. Amiri, A.S.N. Sadat, R. Golzari, J. Med. Plants Res. 5, 4393 (2011)

28. A. Motavalizadehkakhky, A. Shafaghat, H.A. Zamani, H. Akhlaghi, M. Mohammadhosseini, J. Mehrzad, Z. Ebrahimi, J. Med. Plants Res. 7, 1280 (2013)

29. C. Bekhechi, F.A. Bekkara, J. Casanova, F. Tomi, J. Essent. Oil Res. 23, 42 (2011)

30. A. Motavalizadehkakhky, Z. Ebrahimi, R. Emamiyan, A. Mohamadian, F. Abedi, Asian J. Chem. 25, 6372 (2013) 